\title{
Development of equations and proposed reference values to estimate body fat mass among Chilean children and adolescents
}

\author{
Marco Cossio-Bolaños, M.D. ${ }^{a, b, c}$, Miguel de Arruda, M.D. ${ }^{a}$, José Sulla Torres, M.D. ${ }^{d}$, \\ Camilo Urra Albornoz, Magister and Rossana Gómez Campos, M.D. ${ }^{a, f}$
}

\begin{abstract}
Introduction. The assessment of body composition is relevant to establish nutritional status and identify potential health risks.

Objective. a) To develop regression equations to predict fat mass (FM) using a dual-energy $\mathrm{X}$-ray absorptiometry as reference method; b) to propose reference FM values based on chronological and biological age for Chilean children and adolescents.

Methodology. Cross-sectional study in children and adolescents aged 5.0 to 18.9 years from the Maule Region(Chile). The sample was made up of 3593 subjects in a probabilistic fashion (stratified). Subjects' weight, standing height, sitting height, and waist circumference were assessed. Body massindex and age at peak development velocity (APGV) were estimated. Body composition (FM, fat-free mass, bone mass, and fat percentage) were established based on a dual-energy X-ray absorptiometry scan.

Results. APGV (biological age)was $14.9 \pm 0.9$ years among boys and $11.5 \pm 0.7$ among girls. Equations were developed to estimate FM among boys and girls using chronological age, APGV, and waist circumference as predictors. Percentiles were estimated to assess FM by dual-energy $\mathrm{X}$-ray absorptiometry and regression equations.

Conclusion. Equations were acceptable to establish FM; in addition, reference values were proposed to assess FM based on chronological and biological age.

Key words: body composition, prediction equations, $X$-ray absorptiometry, child, adolescent.

http: / / dx.doi.org/10.5546/ aap.2017.eng.453

To cite: Cossio-Bolaños M, de Arruda M, Sulla Torres J, et al. Development of equations and proposed reference values to estimate body fat mass among Chilean children and adolescents. Arch Argent Pediatr 2017;115(5):453-461.
\end{abstract}

\section{INTRODUCTION}

An adequate assessment of body composition is very important to identify potential health risks, especially those related to an excess or a deficiency of different body components. ${ }^{1}$ Measuring fat mass (FM) and fat-free mass (FFM) is particularly interesting in the assessment of nutritional status among children, adolescents, and adults.

An increase in body fat is associated with a greater risk for diseases, including obesity, cardiovascular disease, type 2 diabetes, and hypertension, ${ }^{2}$ and a reduced muscle mass is related to a history of fractures among children, adolescents, and adults. ${ }^{3,4}$

Body composition during childhood and adolescence can be assessed by sophisticated techniques, ${ }^{5,6}$ such as hydrostatic weighing, electric conductivity, bioelectrical impedance, isotope dilution, potassium-40 content, and dual energy X-ray absorptiometry (DXA). ${ }^{6,7}$

Most studies conducted in children and adolescents that identify the size of the problem and healthrelated consequences resulting from overweight and obesity use international body mass index (BMI) references based on age and sex; 8 however, to our knowledge, in Chile there are no national references in place to estimate fat percentage (F\%) and/or FM, specifically among children and adolescents. Such type of reference may improve public health surveillance, facilitate the detection of clinical conditions, and make advancements in research to prevent obesity ${ }^{8}$ in clinical and epidemiological contexts. 
This study proposes the hypothesis that anthropometric outcome measures, such as chronological and biological age, may predict FM among children and adolescents. Previous studies have demonstrated their usefulness and applicability as a non-invasive method to analyze body composition. , $9,10^{10}$

In this context, an accurate FM measurement would mean developing age- and sex-specific reference standards, especially in a setting such as the Chilean population, who have the highest overweight and obesity rates in Latin America. ${ }^{11,12}$ The objectives of this study were a) to develop regression equations to predict FM, using a DXA as a reference method, and $b$ ) to propose reference values based on chronological and biological age for children and adolescents from the Maule Region (Chile).

\section{MATERIAL AND METHODS \\ Sample and study}

This was a cross-sectional study conducted in children and adolescents aged 5.0 to 18.9 years from the Maule Region (Chile). Four municipalities were included (Cauquenes, Curicó, Linares, and Talca).

Students included in the study attended one of 12 primary and secondary public schools in this region. The schools were selected by convenience (participation availability). The sample was made up of 25668 students (14 374 boys and 11294 girls). The sample size was estimated on a probabilistic fashion (stratification with proportional allocation) (95\% confidence interval), reaching $14.0 \%$ (3593 subjects, 1950 boys and 1643 girls). The number of sample elements from each stratum was directly proportional to the stratum size (age and sex) within the population.

Students were transferred by bus from their respective schools to the facilities of Universidad Autónoma de Chile (Laboratory) and back to school during school hours.

Subjects were eligible if they were between 5.0 and 18.9 years old and came from non-smoking families. Students with physical disabilities that prevented them from moving on their own, or had had a respiratory problem in the past 3 weeks, or had metal implants and / or prostheses were excluded. Data were collected in a card prior to performing the DXA scan.

Prior to obtaining the informed consent, the study objectives and the methods to be used were explained to parents and/or legal tutors. Parents signed an informed consent to authorize the anthropometric evaluations and DXA scans to be performed on their children. An informed assent was also obtained from children and adolescents. In addition, authorizations were obtained from the Municipal Administration of Education of Talca and from the principals of the schools included in the study. The study was also approved by the Ethics Committee of Universidad Autónoma de Chile (Chile) and was conducted in accordance with the Declaration of Helsinki. Once the project was completed, every parent and/or legal tutor received the results of the anthropometric and body composition assessment of their children.

\section{Procedures}

Data, such as date of birth, sex, and home address, were obtained from each school principal's office. Anthropometric assessments and DXA scans were performed between August and November 2015, from Mondays through Fridays between 8:00 AM and 1:00 PM and between 2:00 PM and 6:00 PM, at a closed laboratory $\left(20-24{ }^{\circ} \mathrm{C}\right)$ in Universidad Autónoma de Chile (Talca, Chile). The assessment of anthropometric outcome measures and DXA scans lasted between 10 and 12 minutes per student. Both procedures were performed by highly trained staff members.

The protocol standardized by Ross, MarfellJones ${ }^{13}$ was used to obtain anthropometric outcome measures. Body weight $(\mathrm{kg})$ was measured using an electronic scale (Tanita, United Kingdom, Ltd), with a 100 g precision and a range from 0 to $150 \mathrm{~kg}$. Standing height was measured using a portable stadiometer (Seca Gmbh \& Co. KG, Hamburg, Germany) with an $0.1 \mathrm{~mm}$ precision, and adjusted to the Frankfurt plane. Sitting height (trunk length + head length) was measured with the aid of a 50-cm-tall wooden bench, with a $1 \mathrm{~mm}$ precision and a range from 0 to $150 \mathrm{~cm}$. Waist circumference (WC) was measured in $\mathrm{cm}$ at the midline between the lower ribs and the upper portion of the iliac crest using a Seca metal tape measure graduated in millimeters with a $0.1 \mathrm{~cm}$ precision. Assessments were conducted by 4 anthropometrists (the authors of this article). BMI was estimated based on the following formula: $\mathrm{BMI}=$ weight $(\mathrm{kg}) /$ height $^{2}(\mathrm{~m})$.

Biological maturation was established based on the age at peak growth velocity (APGV). The regression equation proposed by Mirwald et al. ${ }^{14}$ was used to predict it. This technique helps to classify it into levels (positive or negative), 
indicating the moment before or after the peak of growth velocity (PGV). Zero (0) means the moment at which APGV occurs. Biological age occurred at levels -7 to 3 APGV in boys and -6 to 8 APGV in girls.

A DXA (Lunar Prodigy; General Electric, Fairfield, CT) was used for scanning the entire body (leaving out the head). Assessments were conducted at a single laboratory and using a single densitometer. Fat $\%$, bone mass, FFM, and FM values were obtained. The procedure was conducted with the subjects lying in the supine position on the assessment platform, with their arms and legs extended (pronation). Their ankles were held with a Velcro fastening tape to ensure they remained in the standard position. Subjects were asked if they had any metal piece in their body that might hinder the scanning procedure. The assessment was conducted by 2 highly experienced technicians in charge of calibrating the equipment on a daily basis.

As a quality control of outcome measures collected in the study, $10 \%$ of the total sample was assessed twice (189 boys and 170 girls). The testretest technique was used for the anthropometric assessment and the DXA scan. The standard error of the mean (SEM) for anthropometric outcome measures was below $2.0 \%$, and for DXA values, below $3.2 \%$.

\section{Statistics}

The normal distribution of data was verified using the Kolmogorov-Smirnov test. A descriptive statistical analysis was performed to establish the arithmetic mean and the standard deviation. Differences between sexes were obtained using Student's $t$ test for independent samples. The relationship among outcome measures was estimated using Pearson's correlation coefficient. Four regression models were developed to predict FM ( 2 for boys and 2 for girls). A stepwise multiple regression analysis was done to identify the best combination of FM predictive outcome measures. Equations were analyzed using the R2, SEM, and multicollinearity by means of the variance inflation factor (VIF). A Bland-Altman plot ${ }^{15}$ was used to verify agreement between the reference method (DXA) and the equations developed. Smoothed percentile curves for FM were created based on each age group and sex according to the least-mean-square algorithm (LMS). ${ }^{16}$ The LMS Chartmaker software, version 2.3., was used. ${ }^{17}$ The final percentile curves were smoothed to create 3 age-specific curves: L (lambda, asymmetry), M (mu, median), and $\mathrm{S}$ (sigma, coefficient of variation). The p5, p10, p50, p85, and p95 percentiles were estimated. The level of significance was set at 0.001 . Estimations were processed using Excel spreadsheets and the SPSS 16.0 software.

\section{RESULTS}

Outcome measures characteristic of the studied sample are shown in Table 1. Boys had a higher weight, standing height, sitting height, WC, lean body mass, and bone mass compared to girls $(p<0.001)$. On the contrary, girls had a higher FM and F\% relative to boys $(p<0.001)$.

TABLE 1. Anthropometric and body composition characteristics of the studied sample

\begin{tabular}{|c|c|c|c|c|}
\hline \multirow[b]{2}{*}{ Outcome measures } & \multicolumn{2}{|c|}{ Boys $(n=1950)$} & \multicolumn{2}{|c|}{ Girls (n=1643) } \\
\hline & $\mathbf{x}$ & SD & $\mathrm{X}$ & SD \\
\hline Chronological age (years) & 13.4 & 3.8 & 12.4 & 3.7 \\
\hline Biological age (APGV) & 14.9 & $0.9^{*}$ & 11.5 & 0.7 \\
\hline \multicolumn{5}{|l|}{ Anthropometry } \\
\hline Weight $(\mathrm{kg})$ & 54.6 & $19.8^{*}$ & 47.8 & 16.7 \\
\hline Standing height $(\mathrm{cm})$ & 155.4 & $19.7^{*}$ & 146.5 & 15.5 \\
\hline Sitting height $(\mathrm{cm})$ & 81.1 & $10.5^{*}$ & 77.0 & 8.6 \\
\hline Waist circumference $(\mathrm{cm})$ & 72.9 & $12.0^{*}$ & 69.3 & 11.0 \\
\hline $\mathrm{BMI}\left(\mathrm{kg} / \mathrm{m}^{2}\right)$ & 21.7 & 4.6 & 21.5 & 4.6 \\
\hline \multicolumn{5}{|l|}{ Body composition (DXA) } \\
\hline Fat mass $(\mathrm{kg})$ & 13.7 & $7.6^{*}$ & 16.8 & 8.3 \\
\hline Fat-free mass $(\mathrm{kg})$ & 38.8 & $14.4^{*}$ & 29.3 & 9 \\
\hline Bone mass $(\mathrm{kg})$ & 2.1 & $0.8^{*}$ & 1.6 & 0.5 \\
\hline Fat percentage (fat $\%$ ) & 26.1 & $8.7^{*}$ & 35.2 & 6.4 \\
\hline
\end{tabular}

$\mathrm{X}$ : average; SD: standard deviation; APGV: age at peak growth velocity; BMI: body mass index;

*: significant difference from girls $(p<0.005)$. 
APGV (biological age) was $14.9 \pm 0.9$ years among boys and $11.5 \pm 0.7$ among girls. In addition, no significant differences were observed in terms of chronological age and BMI between both sexes $(p>0.05)$.

Four regression equations were proposed (Table 2) to predict FM among male and female children and adolescents. Two equations were based on chronological age (equations 1 and 3) and the other two, on biological age (equations 2 and 4). For all equations, inflation values ranged between 1.47 and 1.55 . The percentage of explained adjusted $\mathrm{R}$ for the 2 equations corresponding to boys reached $64 \%$ and for the 2 corresponding to girls, $73 \%$. In all cases, SEM values were below $4.65 \%$.

Agreement between both methods (reference method and equations) is shown in Figure 1. The 4 equations developed for both boys and girls showed ample agreement limits compared to the reference method. Such limits went from -10.42 to $11.53 \mathrm{~kg}$ for boys and from -9.74 to $10.51 \mathrm{~kg}$ for girls. Also, correlations in the 4 plots ranged between 0.79 and 0.85 , and were highly significant $(p<0.001)$.

TABLE 2. Development of specific regression equations to estimate fat mass among children and adolescents

\begin{tabular}{|c|c|c|c|c|c|c|c|}
\hline No. & Equations & VIF & & $\mathbf{R}$ & $\mathbf{R}^{2}$ & SEM & $p$ \\
\hline & Boys $(\mathrm{n}=1950)$ & & & & & & \\
\hline \multirow[t]{2}{*}{1} & $\mathrm{FM}=-22.059-0.45 *$ age $+0.573 * \mathrm{WC}$ & Age & 1.55 & 0.8 & 0.64 & 4.65 & 0.000 \\
\hline & & WC & 1.55 & & & & \\
\hline \multirow[t]{3}{*}{2} & $\mathrm{FM}=-29.401-0.65 * \mathrm{APGV}+0.58 * \mathrm{WC}$ & APGV & 1.61 & 0.8 & 0.64 & 4.64 & 0.000 \\
\hline & & WC & 1.61 & & & & \\
\hline & Girls $(n=1643)$ & & & & & & \\
\hline \multirow[t]{2}{*}{3} & $\mathrm{FM}=-26.329+0.362 *$ age $+0.558 * \mathrm{WC}$ & Age & 1.47 & 0.85 & 0.73 & 4.42 & 0.000 \\
\hline & & WC & 1.47 & & & & \\
\hline \multirow[t]{2}{*}{4} & $\mathrm{FM}=-19.779+0.459 * \mathrm{APGV}+0.521 * \mathrm{WC}$ & APGV & 1.71 & 0.85 & 0.73 & 4.35 & 0.000 \\
\hline & & WC & 1.71 & & & & \\
\hline
\end{tabular}

FM: fat mass; APGV: age at peak growth velocity; WC: waist circumference; VIF: variance inflation factor; SEM: standard error of the mean.

FIGURE 1. Bland-Altman plot of agreement among fat mass values obtained with the reference method (DXA) and the 4 specific equations: figures 1. A and 1. B show agreement with equations 1 and 3. Figures 1. C and 1. D show agreement with equations 2 and 4
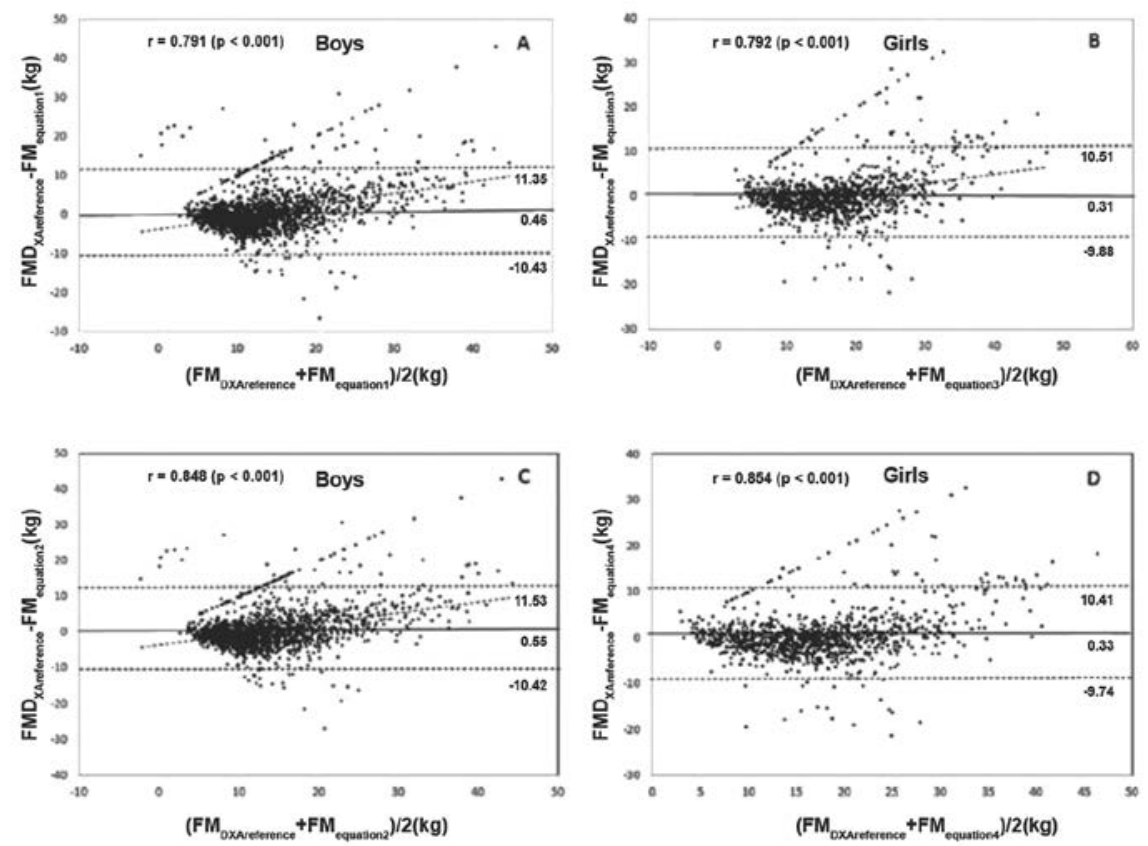

FM: fat mass; DXA: dual-energy X-ray absorptiometry. 
Figure 2 shows the comparison among the reference average values (DXA) and the 4 specific equations ( 2 for boys, A-C, and 2 for girls, B-D). No significant differences were observed in the 4 plots $(p>0.05)$; this indicates that the 4 equations reflected similar results compared to the reference method (DXA).

The percentile distribution to assess FM based on the reference method (DXA) and the regression equations is shown in Tables 3 and 4. The values from Table 3 can be used to make comparisons based on chronological age, and those from Table 4, based on biological age. For boys, both percentiles (reference method versus equations) differed between -2.0 and $1.6 \mathrm{~kg}$ whereas for girls, the difference ranged between -2.5 and $2.5 \mathrm{~kg}$. In general, median values for both boys and girls increased alongside chronological and biological age.

\section{DISCUSSION}

The outcome measures chosen to develop equations to predict FM are chronological age, biological age, and WC. These are the outcome measures usually used in clinical practice, the education system, sports science, and epidemiological research.
Previous studies have proposed regression equations based on anthropometric outcome measures and chronological age to estimate body fat $\%$ in samples of pediatric individuals, which were considered small sample sizes; $;^{18-22}$ however, to our knowledge, this is the first study conducted in Chile that included the development of regression equations to estimate $\mathrm{FM}$ in a representative sample size and using a DXA as the reference method.

The 4 regression equations developed here evidenced moderately accurate coefficients of regression as described in the bibliography, ${ }^{23,24}$ given that the $\mathrm{R} 2$ reached a $64 \%$ explanation among boys, and $73 \%$ among girls. In addition, the proposed equations showed an adequate level of agreement when compared to the DXA reference method because $95 \%$ confidence limits were relatively narrow, and even correlation coefficients were significant, between 0.79 and 0.85 .

VIFs were lower than values established as normal $(>0.10,<10.0)$, as described by Slinker and Glantz, ${ }^{25}$ and SEMs were lower than the 5\% suggested by Lohman. ${ }^{26}$ No significant differences were observed between the reference method (DXA) and the equations. These results suggest

FIGURE 2. Comparison among mean values for the reference method (DXA) and the 4 equations (2. A with equation 1 , 2. B with equation 3, 2. C with equation 2, and 2. D with equation 4)
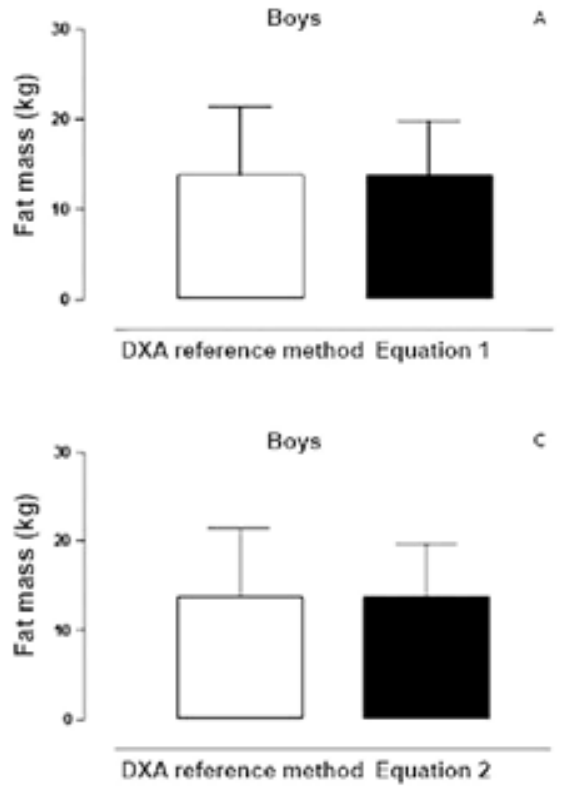
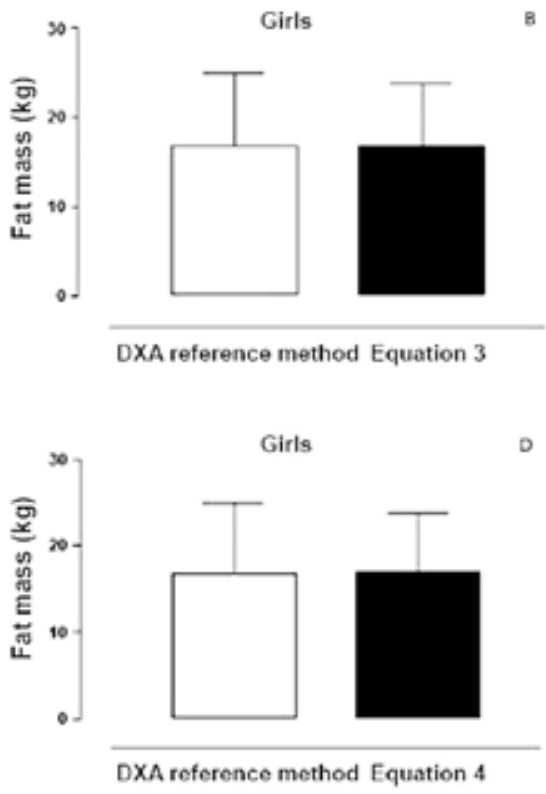

DXA: dual-energy X-ray absorptiometry. 
that the prediction of FM among children and adolescents from the Maule Region (Chile) is adequately accurate.

The 4 prediction equations developed to estimate FM among male and female students may potentially be used for large scale studies as they allow to predict obesity based on chronological and biological age. The 4 equations included WC because this anthropometric outcome measure is very commonly used to assess abdominal fat in different age groups. In this context, anthropometry is a widely used tool to develop regression equations for the estimation of body composition. This field technique is known to be easy and simple, and also low- $\operatorname{cost}^{27}$ compared to laboratory or reference methods, which are still insufficient for their adequate use in field and clinical research, respectively. ${ }^{10}$
In relation to the proposed reference values to estimate FM based on chronological and biological age, percentiles have been developed on the basis of data obtained from DXA and regression equations by age and sex.

The cut-off points adopted in this study are p10, p85, and p95, which reflect a low weight, a normal weight, and overweight and obesity, respectively. These parameters were chosen based on international studies that use BMI as the main criterion to classify body fat, ${ }^{16,28}$ although, in general, the definition of excess body fat in growing populations is quite arbitrary. ${ }^{29}$ To our knowledge, there is not a definite consensus as to which indicators or parameters should be used to define obesity or even the cut-off points to be adopted. Reference standards, either national and/or international, currently in force,

TABLE 3. Percentiles based on the LMS method to assess fat mass among children and adolescents based on chronological age and $\operatorname{sex}$

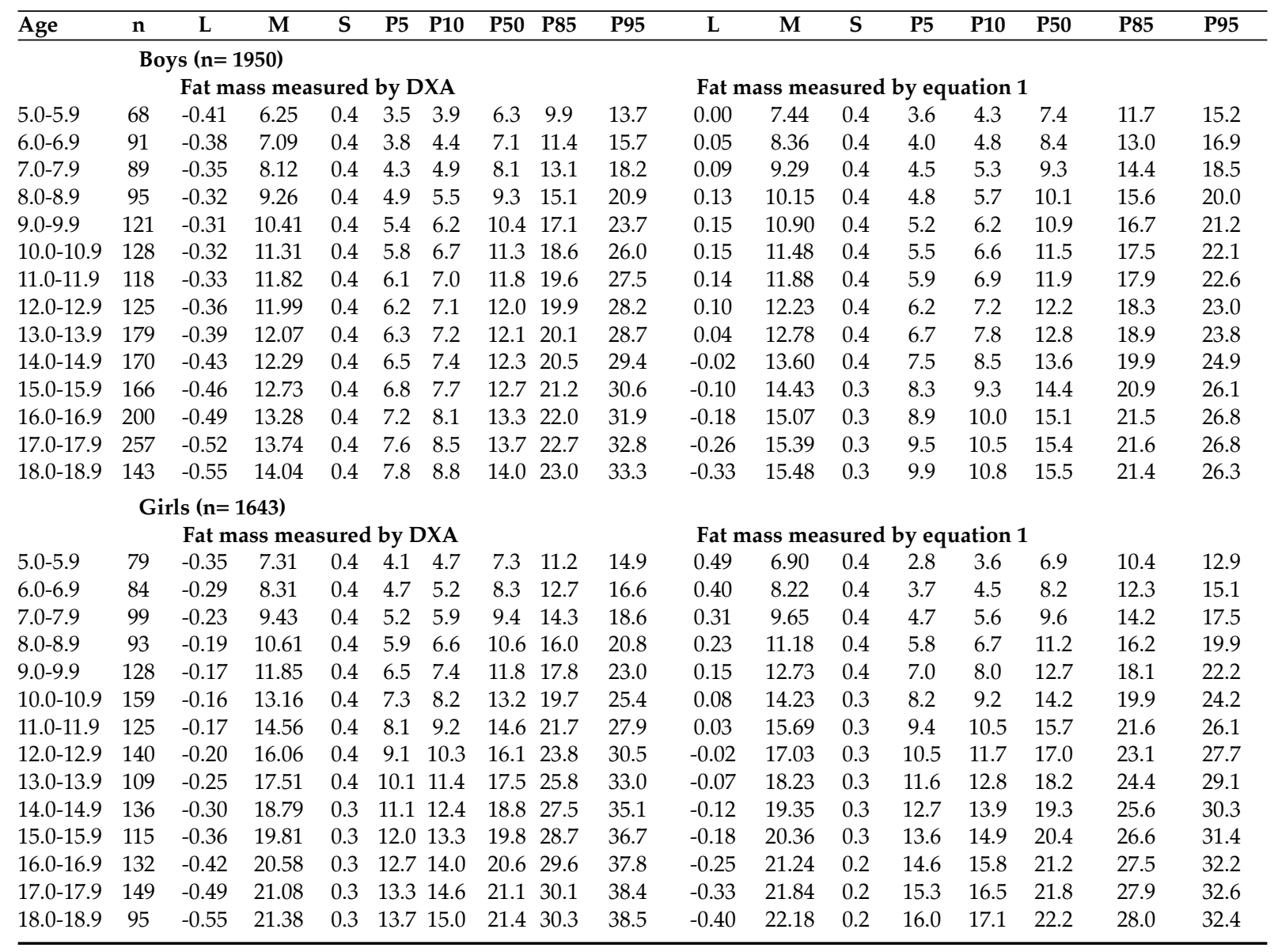


are subject to potential bias, ${ }^{30}$ which should be taken into consideration before their use and implementation.

It is important to point out that this study provides percentile values for FM obtained based on a sophisticated method (DXA) and on an alternative method (anthropometry). Body fat measurement using this sophisticated technique is superior to indirect measurements in terms of accuracy; ${ }^{31}$ however, when such complex equipment is not available, it is better to use widely available and simple techniques, e.g. anthropometry, ${ }^{32}$ which enable to infer approximate FM values for different populations.

In this context, regardless of the technique used in this study, determining excess FM among children and adolescents could help to identify individuals with a greater chance of developing risk factors associated with type 2 diabetes mellitus, cardiovascular disease, hypertension, and cancer, ${ }^{33}$ and subjects with psychosocial complications resulting from excessive body fat. ${ }^{34}$

The findings of this study were not designed to be decisive for the determination of FM in each child and/or adolescent, but rather, to account for the typical levels of body fat in the population of the Maule Region (Chile) at present; therefore, assessment results can be used as indicators of health and well-being because they reflect nutritional status and living conditions $\mathrm{s}^{35}$ of a subject or, in this particular case, of a specific geographic region. The results of this study suggest that they should be used and implemented in clinical and epidemiological settings.

The strengths of this study are its sample size, the wide age range (5.0-18.9 years old), the control of biological maturation, and the development of equations to predict FM among children and adolescents in a fast, cost-effective, and simple

TABLE 4. Percentiles based on the LMS method to assess fat mass among children and adolescents based on biological age and sex

\begin{tabular}{|c|c|c|c|c|c|c|c|c|c|c|c|c|c|c|c|c|c|}
\hline APGV & $\mathbf{n}$ & $\mathbf{L}$ & $\mathbf{M}$ & $\mathbf{S}$ & P5 & P10 & P50 & P85 & P95 & $\mathbf{L}$ & $\mathbf{M}$ & $\mathbf{S}$ & P5 & P10 & P50 & P85 & P95 \\
\hline \multicolumn{18}{|c|}{ Boys $(n=1950)$} \\
\hline \multicolumn{8}{|c|}{ Fat mass measured by DXA } & \multicolumn{10}{|c|}{ Fat mass measured by equation 2} \\
\hline-7 & 41 & -0.53 & 5.50 & 0.40 & 3.1 & 3.5 & 5.5 & 8.8 & 12.3 & 0.13 & 6.19 & 0.49 & 2.7 & 3.2 & 6.2 & 10.1 & 13.2 \\
\hline-6 & 126 & -0.44 & 6.83 & 0.41 & 3.8 & 4.3 & 6.8 & 10.9 & 15.2 & 0.17 & 7.47 & 0.47 & 3.3 & 4.0 & 7.5 & 11.9 & 15.4 \\
\hline-5 & 164 & -0.36 & 8.61 & 0.42 & 4.6 & 5.3 & 8.6 & 13.8 & 19.0 & 0.19 & 8.99 & 0.45 & 4.0 & 4.9 & 9.0 & 14.1 & 18.1 \\
\hline-4 & 184 & -0.31 & 10.46 & 0.43 & 5.5 & 6.3 & 10.5 & 16.9 & 23.2 & 0.19 & 10.34 & 0.44 & 4.8 & 5.7 & 10.3 & 16.0 & 20.3 \\
\hline-3 & 159 & -0.30 & 11.71 & 0.44 & 6.1 & 7.0 & 11.7 & 19.1 & 26.3 & 0.15 & 11.22 & 0.42 & 5.4 & 6.4 & 11.2 & 17.1 & 21.7 \\
\hline-2 & 161 & -0.32 & 12.17 & 0.44 & 6.3 & 7.2 & 12.2 & 20.0 & 27.9 & 0.07 & 11.79 & 0.40 & 6.0 & 7.0 & 11.8 & 17.8 & 22.5 \\
\hline-1 & 169 & -0.37 & 12.30 & 0.44 & 6.4 & 7.3 & 12.3 & 20.4 & 28.8 & -0.02 & 12.58 & 0.38 & 6.7 & 7.7 & 12.6 & 18.7 & 23.7 \\
\hline 0 & 225 & -0.43 & 12.54 & 0.44 & 6.7 & 7.6 & 12.5 & 20.9 & 29.9 & -0.11 & 13.59 & 0.36 & 7.6 & 8.6 & 13.6 & 19.9 & 25.2 \\
\hline 1 & 329 & -0.50 & 13.13 & 0.43 & 7.1 & 8.0 & 13.1 & 21.8 & 31.6 & -0.16 & 14.40 & 0.35 & 8.4 & 9.4 & 14.4 & 20.8 & 26.2 \\
\hline 2 & 321 & -0.58 & 13.88 & 0.42 & 7.7 & 8.7 & 13.9 & 23.0 & 33.8 & -0.19 & 14.92 & 0.33 & 8.9 & 9.9 & 14.9 & 21.3 & 26.6 \\
\hline 3 & 71 & -0.66 & 14.48 & 0.41 & 8.3 & 9.2 & 14.5 & 24.0 & 35.8 & -0.21 & 15.24 & 0.32 & 9.2 & 10.3 & 15.2 & 21.5 & 26.7 \\
\hline \multicolumn{18}{|c|}{ Girls $(n=1643)$} \\
\hline \multicolumn{8}{|c|}{ Fat mass measured by DXA } & \multicolumn{10}{|c|}{ Fat mass measured by equation 4} \\
\hline-6 & 69 & -0.13 & 6.72 & 0.35 & 3.8 & 4.3 & 6.7 & 9.8 & 12.3 & 0.43 & 5.66 & 0.43 & 2.4 & 3.0 & 5.7 & 8.5 & 10.5 \\
\hline-5 & 115 & -0.12 & 8.04 & 0.35 & 4.6 & 5.2 & 8.0 & 11.7 & 14.7 & 0.32 & 7.24 & 0.40 & 3.5 & 4.1 & 7.2 & 10.7 & 13.2 \\
\hline-4 & 108 & -0.11 & 9.41 & 0.35 & 5.4 & 6.1 & 9.4 & 13.7 & 17.2 & 0.20 & 8.88 & 0.37 & 4.6 & 5.4 & 8.9 & 12.9 & 15.9 \\
\hline-3 & 103 & -0.11 & 10.72 & 0.35 & 6.1 & 6.9 & 10.7 & 15.5 & 19.5 & 0.10 & 10.49 & 0.35 & 5.8 & 6.6 & 10.5 & 15.0 & 18.3 \\
\hline-2 & 121 & -0.11 & 11.95 & 0.35 & 6.9 & 7.7 & 11.9 & 17.3 & 21.6 & 0.02 & 12.02 & 0.32 & 7.0 & 7.9 & 12.0 & 16.8 & 20.4 \\
\hline-1 & 132 & -0.12 & 13.11 & 0.35 & 7.6 & 8.5 & 13.1 & 18.9 & 23.6 & -0.05 & 13.48 & 0.30 & 8.3 & 9.2 & 13.5 & 18.5 & 22.3 \\
\hline 0 & 107 & -0.14 & 14.26 & 0.34 & 8.3 & 9.3 & 14.3 & 20.5 & 25.6 & -0.11 & 14.82 & 0.28 & 9.4 & 10.4 & 14.8 & 19.9 & 23.8 \\
\hline 1 & 104 & -0.17 & 15.47 & 0.33 & 9.1 & 10.2 & 15.5 & 22.1 & 27.5 & -0.15 & 16.07 & 0.26 & 10.6 & 11.6 & 16.1 & 21.2 & 25.1 \\
\hline 2 & 109 & -0.20 & 16.73 & 0.33 & 10.0 & 11.2 & 16.7 & 23.8 & 29.6 & -0.17 & 17.22 & 0.25 & 11.6 & 12.6 & 17.2 & 22.4 & 26.3 \\
\hline 3 & 114 & -0.24 & 17.92 & 0.32 & 10.9 & 12.1 & 17.9 & 25.3 & 31.5 & -0.17 & 18.24 & 0.24 & 12.5 & 13.6 & 18.2 & 23.4 & 27.2 \\
\hline 4 & 136 & -0.27 & 19.10 & 0.31 & 11.8 & 13.0 & 19.1 & 26.9 & 33.3 & -0.16 & 19.31 & 0.23 & 13.5 & 14.6 & 19.3 & 24.5 & 28.3 \\
\hline 5 & 142 & -0.29 & 20.44 & 0.31 & 12.7 & 14.0 & 20.4 & 28.7 & 35.6 & -0.13 & 20.62 & 0.22 & 14.5 & 15.7 & 20.6 & 25.9 & 29.7 \\
\hline 6 & 147 & -0.29 & 22.08 & 0.31 & 13.7 & 15.1 & 22.1 & 31.0 & 38.4 & -0.09 & 22.29 & 0.21 & 15.9 & 17.1 & 22.3 & 27.8 & 31.7 \\
\hline 7 & 97 & -0.29 & 23.99 & 0.31 & 14.9 & 16.4 & 24.0 & 33.7 & 41.9 & -0.06 & 24.24 & 0.21 & 17.4 & 18.7 & 24.2 & 30.0 & 34.1 \\
\hline 8 & 39 & -0.29 & 26.10 & 0.32 & 16.1 & 17.8 & 26.1 & 36.8 & 45.7 & -0.02 & 26.36 & 0.20 & 19.0 & 20.4 & 26.4 & 32.5 & 36.7 \\
\hline
\end{tabular}

LMS: Least-Mean-Square algorithm; L: Box-Cox power; M: median; S: coefficient of variation;

DXA: dual-energy X-ray absorptiometry. 
manner. This study has certain limitations, such as the fact that the equations developed in this study may not be valid for other ethnic groups because it was not possible to perform crossvalidation and should therefore be analyzed and used with caution. Future studies should consider the possibility of including other body perimeters and skinfolds in equations to estimate total body FM in addition to specific body regions.

\section{CONCLUSION}

Equations developed in this study showed that they were acceptable to determine FM among male and female children and adolescents. Reference values have been proposed to assess FM by means of a DXA and regression equations based on chronological and biological age. Such percentiles offer additional information for epidemiological and clinical research to diagnose, classify, monitor, and control health risks associated with overweight and obesity among children and adolescents. Estimations may be done in the following web site:

http: / / reidebihu.net/masagrasa.php.

\section{REFERENCES}

1. Langer RD, Borges JH, Pascoa MA, et al. Validity of Bioelectrical Impedance Analysis to Estimation Fat-Free Mass in the Army Cadets. Nutrients 2016;8(3):121.

2. Seidell JC, Hautvast JG, Deurenberg P. Overweight: Fat distribution and health risks. Epidemiological observations. A review. Infusions Therapie 1989;16(6):276-81.

3. Schoenau E, Neu CM, Beck B, et al. Bone Mineral Content per muscle cross-sectional area as an index of the functional muscle-bone unit. J Bone Miner Res 2002;17(6):1095-101.

4. Popp KL, Hughes JM, Smock AJ, et al. Bone geometry, strength, and muscle size in runners with a history of stress fracture. Med Sci Sports Exer 2009:41(12):2145-50.

5. Goran MI, Driscoll P, Johnson R, et al. Cross-calibraton of body composition techniques against dual-energy X-ray absorptiometry in young children. Am J Clin Nutr 1996;63(3):299-305.

6. Silva AM, Minderico CS, Teixeira PJ, et al. Body fat measurement in adolescent athletes: Multicompartment molecular model comparison. Eur J Clin Nutr 2006;60(8): 955-64.

7. Wong WW, Stuff JE, Butte NF, et al. Estimating body fat in African American and white adolescent girls: a comparison of skinfold-thickness equations with a 4-compartment criterion model. Am J Clin Nutr 2000;72(2):348-54.

8. Laurson KR, Eisenmann JC, Welk GJ. Body Fat Percentile Curves for U.S. Children and Adolescents. Am J Prev Med 2011;41(4 Suppl 2):S87-92.

9. Iuliano-Burns S, Mirwald RL, Bailey DA. Timing and magnitude of peak height velocity and peak tissue velocities for early, average, and late maturing boys and girls. Am J Hum Biol 2001;13(1):1-8.

10. Rodríguez G, Moreno LA, Blay MG, et al. Body fat measurement in adolescents: comparison of skinfold thickness equations with dual-energy X-ray absorptiometry. Eur J Clin Nutr 2005;59(10):1158-66.
11. $\mathrm{Ng} \mathrm{M}$, Fleming $\mathrm{T}$, Robinson $\mathrm{M}$, et al. Global, regional, and national prevalence of overweight and obesity in children and adults during 1980-2013: a systematic analysis for the Global Burden of Disease Study 2013. Lancet 2014;384(9945):766-81.

12. Lopez-Legarrea P, Olivares PR, Almonacid-Fierro A, et al. Association between dietary habits and the presence of overweight/obesity in a sample of 21,385 Chilean adolescents. Nutr Hosp 2015;31(5):2088-94.

13. Ross WD, Marfell-Jones MJ. Kinanthropometry. In: MacDougallJD, Wenger HA, Geeny HJ, eds. Physiological testing of elite athlete. London: Human Kinetics; 1991: 223-308.

14. Mirwald RL, Baxter-Jones ADG, Bailey DA, et al. An assessment of maturity from anthropometric measurements. Med Sci Sports Exerc 2002;34(4):689-94.

15. Bland JM, Altman DG. Statistical methods for assessing agreement between two methods of clinical measurement. Lancet 1986;8(8476):307-10.

16. ColeTJ, Bellizzi MC, Flegal KM, etal. Establishing a standard definition for child overweight and obesity worldwide: International survey. BMJ 2000;320(7244):1240-3.

17. Pan H, Cole TJ. LMS Chartmaker. 2006. [Accessed on: March $\left.28^{\text {th }}, 2015\right]$. Available at: http:/ / www.healthforallchildren. co.uk.

18. Slaughter MH, Lohman TG, Boileau RA, et al. Skinfold equations for estimation of body fatness in children and youth. Hum Biol 1988;60(5):709-23.

19. Bray GA, DeLany JP, Volaufova J, et al. Prediction of body fat in 12-y-old African American and white children: evaluation of methods. Am J Clin Nutr 2002;76(5):980-90.

20. Parker L, Reilly JJ, Slater C, et al. Validity of six field and laboratory methods for measurement of body composition in boys. Obes Res 2003;11(7):852-8.

21. Gómez-Campos R, De Marco A, Arruda M, et al. Predicción de ecuaciones para el porcentaje de grasa a partir de circunferencias corporales en niños pre-púberes. Nutr Hosp 2013;28(3):772-8.

22. Duarte M, Flores Ruelas Y, López-Alcaraz F, et al. Correlation between percentage of body fat measured by the Slaughter equation and bio impedance analysis technique in Mexican schoolchildren. Nutr Hosp 2014;29(1):88-93.

23. Cameron N, Griffiths PL, Wright MM, et al. Regression equations to estimate percentage body fat in African prepubertal children aged 9 y. Am J Clin Nutr 2004;80(1): 70-5.

24. Gartner A, Dioum A, Delpeuch F, et al. Use of hand-to-hand impedancemetry to predict body composition of African women as measured by air displacement plethysmography. Eur J Clin Nutr 2004;58(3):523-31.

25. SlinkerBK, GlantzSA. Multiple regression for physiological data analysis: the problem of multicollinearity. Am J Physiol 1985; 249(1 Pt 2): R1-12.

26. Lohman TG. Dual energy X-ray absorptiometry. In Roche AF, Heymsfield SB, Lohman TG, eds. Human Body Composition. Champaign, IL: Human Kinetics; 1996:63-78.

27. Moon JR, Tobkin SE, Smith AE, et al. Anthropometic estimations of percent body fat in NCAA Division I female athletes: a 4-compartment model validation.J Strength Cond Res 2009;23(4):1068-76.

28. Kuczmarski RJ, Ogden CL, GuoSS, et al. 2000 CDC Growth charts for the United States: Methods and development. Vital Health Stat 2002:(246):1-190.

29. Moreno LA, Mesana MI, González-Gross M, et al. Anthropometric body fat composition reference values in Spanish adolescents. The AVENA Study. Eur J Clin Nutr 2005;60(2):191-6. 
30. Gómez-Campos R, de Arruda M, Hespanhol JE, et al. Referencial values for the physical growth of school children and adolescents in Campinas, Brazil. Ann Hum Biol 2015;42(1):62-9.

31. Dencker M, Thorsson O, Lindén C, et al. BMI and objectively measured body fat and body fat distribution in prepubertal children. Clin Physiol Funct Imaging 2007;27(1):12-6.

32. Bibiloni Mdel M, Pons A, Tur JA. Defining Body Fatness in Adolescents: A Proposal of the Afad-A Classification. PLoS One 2013;8(2):e55849.
33. Gade W, Schmit J, Collins M, et al. Beyond obesity: the diagnosis and pathophysiology of metabolic syndrome. Clin Lab Sci 2010;23(1):51-61.

34. Millstein RA, Carlson SA, Fulton JE, et al. Relationships between body size satisfaction and weight control practices among US adults. Medscape J Med 2008;10(5):119.

35. Molinari L, Gasser T, Largo R. TW3 bone age: RUS/CB and gender differences of percentiles for score and score increments. Ann Hum Biol 2004; 31(4):421-35. 